\title{
Late Intrauterine Foetal Death in a Tertiary Centre of Bangladesh
}

\author{
Most. Sabina Yeasmin 1*, M. Jalal Uddin², Rajat Sanker Roy Biswas², Farah Naz Mabud1, \\ Nishat Anjum Nourin ${ }^{3}$
}

\author{
${ }^{1}$ Department of Obstetrics and Gynaecology, Chattogram Maa-O-Shishu Hospital Medical College, Chattogram, Bangladesh \\ ${ }^{2}$ Chattogram Maa-O-Shishu Hospital Medical College, Chattogram, Bangladesh \\ ${ }^{3}$ Chittagong Medical College Hospital, Chattogram, Bangladesh \\ Email: ^drsabinah@yahoo.com
}

How to cite this paper: Yeasmin, M.S., Uddin, M.J., Biswas, R.S.R., Mabud, F.N. and Nourin, N.A. (2021) Late Intrauterine Foetal Death in a Tertiary Centre of Bangladesh. Open Journal of Obstetrics and Gynecology, 11, 1093-1103.

https://doi.org/10.4236/ojog.2021.119102

Received: May 17, 2021

Accepted: August 31, 2021

Published: September 3, 2021

Copyright (c) 2021 by author(s) and Scientific Research Publishing Inc. This work is licensed under the Creative Commons Attribution International License (CC BY 4.0).

http://creativecommons.org/licenses/by/4.0/

\begin{abstract}
Background: Late intrauterine foetal death (IUFD $>28$ weeks) is a tragedy to mothers and family members. The first step to reduce IUFD is to obtain an accurate and detailed data for IUFD. The present study was done to identify the probable causes of foetal death and determine the risk of recurrence, prevention or corrective action. Methods: This prospective observational study was conducted in a tertiary hospital during a period of one year in Chattogram Maa-O-Shishu Hospital Medical college, from January to December 2018 , on all admitted pregnant women with intrauterine foetal death $(>28$ weeks). Detailed history, clinical examination, associated conditions, mode of delivery, foetal conditions, placenta, condition of cord and investigation reports were analyzed. Results: A total of 188 IUFD were reported amongst 8013 deliveries with its incidence $23.46 / 1000$ live birth and recurrence rate 8.5\%. Maximum (89.89\%) occurred in antepartum period. Mean maternal age 26.03 years. $59 \%$ unbooked cases, $48.93 \%$ belonging to lower class family and maximum (59\%) from slum and rural area. Most of the cases were Multigravidas (59.6\%) and preterm (52.7\%) gestation. Regarding causes of IUFD hypertensive disorders in pregnancy (45.2\%) were commonest, followed by unexplained 24.5\%, diabetes Mellitus and gestational diabetes mellitus (23.9\%), anaemia $20.7 \%$, hypothyroidism $11.2 \%$, oligohydramnios $11.2 \%$, maternal infection $9.6 \%$, antepartum haemorrhage $8.5 \%$, malpresentation $7.44 \%$, intrauterine growth retardation $4.8 \%$, fetal congenital anomalies $4.8 \% \&$ cord accident $4.3 \%$. Maternal complications occurred $14.9 \%$ cases. Those were postpartum haemorrhage $11.2 \%$, sepsis $2.6 \%$, acute renal failure $0.53 \%$ and disseminated intravascular coagulation (DIC) $0.53 \%$. Most of the patients (86.2\%) delivered vaginally. Maximum number of IUFD was seen in birth weight between $1-1.5 \mathrm{~kg}$ (31.4\%), followed by $2-2.5 \mathrm{~kg}(21.8 \%)$. Conclu-
\end{abstract}


sions: HDP, GDM and anaemia were major causes of IUFD. Most of the causes of IUFD may have been preventable by pre-conceptional councelling, regular antenatal checkup, proper screening, early diagnosis and treatment. Large number IUFD remained unexplained. So, to unravel the complex pathophysiology of IUFD further study is needed.

\section{Keywords}

Intrauterine Foetal Death, Antenatal Care, Risk Factors, Prevention, Maternal Complications

\section{Introduction}

"All pregnancy outcome of both maternal and foetal not always ended with good results". Intrauterine foetal death (IUFD) is one of the most emotionally devastating events in the field of obstetrics. It is really distressing for both the parents and the clinicians when it occurs without warning in a pregnancy that has previously seemed entirely normal.

Though the causes of IUFD are multifactorial, it challenges both medical and personal skill of the doctor. So, it is vital to determine the probable causes, the risk of recurrence, prevention and corrective action.

IUFD may be termed as early and late foetal death. WHO/ICD defines stillbirth as the death of a fetus that has reached a birth weight of $500 \mathrm{~g}$, or if birth weight is unavailable, gestational age of 22 weeks or crown-to-heel length of 25 $\mathrm{cm}$ and also recommends using the higher limit $(1000 \mathrm{~g} / 28$ weeks $/ 35 \mathrm{~cm})$ of third trimester stillbirths for international comparisons and reporting. Within this category, ICD classifies late foetal deaths (greater than $1000 \mathrm{~g}$ or after 28 weeks) and early fetal deaths (500 - $1000 \mathrm{~g}$ or 22 - 28 weeks) [1].

Worldwide 3.3 million stillbirths are reported annually, $97 \%$ occurring in developing countries. Only $4 \%$ of cases are registered in developing countries where under reporting is common. It is believed that an additional $1-2$ million of unrecorded stillbirths occur in these developing countries [2]. Bangladesh showed the fastest annual reduction in stillbirth rates among all countries in South Asia over the 2000-2015 period [3]. Notwithstanding this important reduction, Bangladesh is still ranked seventh globally in terms of absolute number of stillbirths, with an estimated 83,000 stillbirth per annum and a stillbirth rate of 25.4 per 1000 birth [4].

With newer advanced techniques of diagnosis and a better understanding of the pathophysiology of IUFD have led to the determination of causes of death in a greater proportion of cases than in the past.

Objectives of our study were to identify the clinical risk factors, probable etiologies of IUFD and maternal complications associated with it. So, we can take possible preventive measures to reduce recurrence of IUFD and maternal complications associated with it. 
Previous studies to identify the clinical risk factors, probable etiologies of IUFD and maternal complications associated with it were done at different countries. But such studies in Bangladesh are very limited till now. Therefore we conducted the study to fill some portion of this gap.

\section{Materials and Methods}

This prospective observational study was conducted in the department of Obstetrics and Gynaecology, Chattogram Maa-O-Shishu Hospital Medical College (CMOSHMC), Chattogram, Bangladesh from January to December 2018. During the study period all (188) the admitted pregnant women with IUFD more than 28 weeks gestation were included in this study after taking informed written consent from patients. All cases of IUFD were diagnosed on clinical examination by absence of foetal movement and heart sound then confirmed by ultrasonograhpy.

Inclusion criteria:

1) All cases of IUFD with gestational age $>28$ weeks.

2) All the cases whose deliveries occurred in our Hospital.

Exclusion criteria:

1) All cases of IUFD with gestational age $<28$ weeks.

2) All those cases admitted but discharged before delivery and never returned to our Hospital.

Detailed history, clinical examination, associated conditions, mode of delivery, details of the foetus, placenta, condition of cord and investigation reports were recorded.

\section{Results}

During the study period, the total number of deliveries were 8013 and the total number of IUFD or stillbirth cases were 188. So, the stillbirth rate was $23.46 \mathrm{per}$ 1000 live birth (Table 1). Antepartum stillbirth was more 169 (89.89\%) than intrapartum stillbirth 19 (10.11\%). Recurrent cases were significant number 16 (8.5\%) (Table 2). Majority of the women (60.6\%) were 20 - 30 years old and mean maternal age at presentation was 26.03 years. Most of the patients came from slum and rural area (59\%) and low socio-economic status $48.93 \%$ (Table 3).

Multigravida (59.6\%) had the maximum number of IUFD when compared to primigravida (40.4\%).

Most (52.7\%) of the IUFD were preterm gestation and maximum number of

Table 1. Intrauterine deaths in the study period.

\begin{tabular}{lccc}
\hline $\begin{array}{c}\text { Total no. of } \\
\text { deliveries }\end{array}$ & $\begin{array}{c}\text { Total no. } \\
\text { of IUFD }\end{array}$ & $\begin{array}{c}\text { Still birth rate } \\
\text { (Per 1000 live birth) }\end{array}$ \\
\hline Total & 8013 & 188 & 23.46 \\
\hline Source: study report: 2018. & &
\end{tabular}


IUFD occurred at 28 - 36 weeks of gestation. Majority (59\%) of the cases had no antenatal visits (Table 4 ).

In our study regarding causes of IUFD, hypertensive disorders in pregnancy constitute the maximum $(45.2 \%)$ of all cases. Pre-eclampsia \& eclampsia together accounted for $41.5 \%$, unexplained $24.5 \%$ which is little higher than the diabetes mellitus and GDM (23.9\%), other causes are anaemia 20.7\%, hypothyroidism 11.2\%, oligohydramnios $11.2 \%$, maternal infection 9.6\%, APH $8.5 \%$, malpresentation $7.44 \%$, IUGR $4.8 \%$, fetal congenital anomalies $4.8 \%$ \& cord accident $4.3 \%$ (Table 5).

Table 2. Antepartum and intrapartum still births with recurrence.

\begin{tabular}{ccc}
\hline & No. of cases & Percentage (\%) \\
\hline Antepartum & 169 & $89.89 \%$ \\
Intrapartum & 19 & $10.11 \%$ \\
Total & 188 & $100 \%$ \\
Recurrence & 16 & $8.5 \%$ \\
\hline
\end{tabular}

Source: study report: 2018 .

Table 3. Maternal socio-demographic characteristics.

\begin{tabular}{cccc}
\hline Variables & Category & No. of patients & Percentage (\%) \\
\hline \multirow{2}{*}{ Age (Years) } & $<20$ & 24 & $12.8 \%$ \\
& $20-30$ & 114 & $60.6 \%$ \\
$*$ Socio-economic & $31-40$ & 47 & $25 \%$ \\
status & $>40$ & 3 & $1.6 \%$ \\
& Low & 92 & $48.93 \%$ \\
& Hiddle & 78 & $41.5 \%$ \\
Residence & Hrban & 18 & $9.6 \%$ \\
& Slum & 77 & $41 \%$ \\
& Rural & 49 & $26 \%$ \\
\hline
\end{tabular}

*Modified Kuppuswamy's socio-economic scales (source: Cardiovasc: j.2017; 10(1): 17-20).

Table 4. Maternal obstetrics characteristics.

\begin{tabular}{cccc}
\hline Variables & Category & No. of patients & Percentage (\%) \\
\hline \multirow{2}{*}{ Gravidity } & Primigravida & 76 & $40.4 \%$ \\
& Multigravida & 112 & $59.6 \%$ \\
Gestational age & $28-36$ weeks & 99 & $52.7 \%$ \\
(Weeks) & $37-40$ weeks & 55 & $29.3 \%$ \\
Antenatal visits & $>40$ weeks & 34 & $18.08 \%$ \\
& Booked cases & 77 & $41 \%$ \\
Past obstetric history & History of IUFD & 111 & $59 \%$ \\
& History of still birth & 9 & $4.8 \%$ \\
& & 12 & $6.4 \%$ \\
\hline
\end{tabular}

Source: Study report 2018. 
Table 5. Causes of IUFD.

\begin{tabular}{|c|c|c|c|}
\hline Variables & Category & $\begin{array}{c}\text { No. of } \\
\text { patients }\end{array}$ & Percentage (\%) \\
\hline \multirow{4}{*}{$\begin{array}{l}\text { Hypertensive disorders } \\
\text { in pregnancy }\end{array}$} & Severe Pre-eclampsia & 69 & $36.7 \%$ \\
\hline & Antepartum Eclampsia & 9 & $4.8 \%$ \\
\hline & Chronic HTN & 7 & $3.7 \%$ \\
\hline & Total & 85 & $45.2 \%$ \\
\hline \multirow{3}{*}{ Antepartum haemorrhage } & Abruptio placenta & 10 & $5.3 \%$ \\
\hline & Placenta preavia & 6 & $3.2 \%$ \\
\hline & Total & 16 & $8.5 \%$ \\
\hline \multirow{3}{*}{ Diabetes } & Diabetes melitus & 9 & $4.8 \%$ \\
\hline & GDM & 36 & $19.15 \%$ \\
\hline & Total & 45 & $23.9 \%$ \\
\hline \multirow{7}{*}{$\begin{array}{l}\text { Congenital anomalies } \\
\text { of fetus }\end{array}$} & Hydrocephalus & 1 & $0.53 \%$ \\
\hline & Anencephaly & 1 & $0.53 \%$ \\
\hline & Multiple anomalies & 3 & $1.6 \%$ \\
\hline & Spina bifida & 1 & $0.53 \%$ \\
\hline & Omphalocele major & 1 & $0.53 \%$ \\
\hline & Hydrops fetalis & 2 & $1.06 \%$ \\
\hline & Total & 9 & $4.8 \%$ \\
\hline \multirow[t]{2}{*}{ Unexplained } & & 46 & $24.5 \%$ \\
\hline & Maternal gastroenteritis & 8 & $4.3 \%$ \\
\hline \multirow[t]{2}{*}{ Infection } & Maternal fever & 10 & $5.3 \%$ \\
\hline & Total & 18 & $9.6 \%$ \\
\hline Thyroid disorder & Hypothyroidism & 21 & $11.2 \%$ \\
\hline \multirow{3}{*}{ Malpresentation } & Breech presentation & 12 & $6.4 \%$ \\
\hline & $\begin{array}{c}\text { Transverse lie } \\
\text { and hand prolapsed }\end{array}$ & 2 & $1.1 \%$ \\
\hline & Total & 14 & $7.44 \%$ \\
\hline \multirow{2}{*}{ IUGR } & Moderate & 3 & \multirow{2}{*}{$4.8 \%$} \\
\hline & Severe & 6 & \\
\hline \multirow{2}{*}{ Oligohydramnios } & Moderate & 4 & \multirow[b]{2}{*}{$11.2 \%$} \\
\hline & Severe & 17 & \\
\hline \multirow{3}{*}{ Anaemia } & Mild & 19 & \\
\hline & Moderate & 18 & $20.7 \%$ \\
\hline & Severe & 2 & \\
\hline \multirow{4}{*}{ Cord accident } & Cord prolapsed & 4 & $2.12 \%$ \\
\hline & Cord around the neck & 3 & $1.6 \%$ \\
\hline & True knot & 1 & $0.53 \%$ \\
\hline & Total & 8 & $4.3 \%$ \\
\hline
\end{tabular}

Source: study report 2018. 
In this study $14.9 \%$ cases, maternal complications occurred. Among those most serious complication was PPH (11.2\%) followed by sepsis (2.6\%), ARF $(0.53 \%)$ and DIC (0.53\%) (Table 6).

Most of the patients $(86.2 \%)$ delivered vaginally, $10.6 \%$ patients delivered by VBAC \& $3.2 \%$ patients undergone LSCS (Table 7).

IUFD was seen more in male babies (60\%) compared to female babies (40\%). Maximum number of IUFD was seen in birth weight between 1 - $1.5 \mathrm{~kg}$ (31.4\%), followed by $2-2.5 \mathrm{~kg}(21.8 \%)$ (Table 8$)$.

\section{Discussion}

Incidence of stillbirth or IUFD among such a small number of patients does not reflect the total hospital incidence of the nation. In our study, incidence of stillbirth or IUFD was 27.76/1000 live birth. Bhatia T et al. [5], Sharma S et al. [6]

Table 6. Maternal complications.

\begin{tabular}{ccc}
\hline Complications & Number of patients & Percentage (\%) \\
\hline PPH & 21 & $11.2 \%$ \\
SEPSIS & 5 & $2.6 \%$ \\
ARF & 1 & $0.53 \%$ \\
DIC & 1 & $0.53 \%$ \\
Total & 28 & $14.9 \%$ \\
\hline
\end{tabular}

Source: Study report 2018.

Table 7. Mode of delivery.

\begin{tabular}{ccc}
\hline Mode of delivery & No. of cases & Percentage \\
\hline VD & 162 & $86.2 \%$ \\
VBAC & 20 & $10.6 \%$ \\
LSCS & 6 & $3.2 \%$ \\
Total & $\mathbf{1 8 8}$ & $\mathbf{1 0 0 \%}$ \\
\hline
\end{tabular}

Source: Study source 2018.

Table 8. Gender \& birth weight of IUFD.

\begin{tabular}{cccc}
\hline \multirow{2}{*}{ variable } & Category & No. of fetuses & Percentage \\
\hline \multirow{2}{*}{ Gender } & Male & 113 & $60 \%$ \\
& Female & 75 & $40 \%$ \\
\hline \multirow{2}{*}{$\begin{array}{c}\text { Foetal birth weight } \\
(\text { gms })\end{array}$} & $>1000$ & 16 & $8.5 \%$ \\
& $>1500-2000$ & 59 & $31.4 \%$ \\
& $>2000-2500$ & 39 & $20.74 \%$ \\
& $>2500-3000$ & 41 & $21.8 \%$ \\
& $>3000-4000$ & 20 & $10.63 \%$ \\
\hline
\end{tabular}

Source: study report 2018. 
and Kanavi J et al. [7], in their study showed hospital incidence of stillbirth or IUFD 23.46/1000 live birth, 36/1000 live birth and 39/1000 live birth respectively. Which were higher rate than our study, in our study incidence was lower, as most of the delivery that is about $53 \%$ of delivery in our country occur at home. Another study done by Halim A et al. [8] reported an incidence of 20.4/1000 live birth which was lower than that of our study. This study was done at district level and population based but our hospital is referral and tertiary hospital. Bangladesh is still ranked seventh globally in terms of absolute number of stillbirths, with an estimated 83,000 stillbirths per annum and a stillbirth rate of 25.4 per 1000 birth [4] which was close to our study.

In our study, maximum still birth (89.89\%) occur in antepartum period which was almost similar to the study done by Bhatia $\mathrm{T}$ et al. [5] where it was $84.06 \%$. Majority of the patients (60.6\%) belonged to the age group of 20 - 30 years which is similar to the studies [5] [6] [7].

The incidence is a higher risk amongst low socioeconomic status. In our study $48.93 \%$ patients came from low socioeconomic status which was similar to the study [6] [9].

In present study maximum (59.6\%) patients were multigravida which was almost near to the study [7] \& study [10] where it was $57 \%$ \& $50.8 \%$ respectively.

The incidence was higher in preterm $(52.7 \%)$ gestations, which was close to the studies [5] [6] [7] [10].

Unlike other studies [7] [10] where the majority were booked cases that was $94.9 \%$ and $98.4 \%$ respectively, in our study majority (59\%) were unbooked cases. It was similar to the another study [6].

When the etiology of IUFD were analysed, leading cause was hypertensive disorders in pregnancy (45.2\%). Hypertensive disorders in pregnancy were the leading cause of IUFD in other studies [5] [6] [7] [8] [10] [11]. Severe pre-eclampsia and antepartum eclampsia were seen $36.7 \%$ and $4.8 \%$ cases respectively which was near to the study [7].

Cases of hypertension in pregnancy were more likely to have placental insufficiency with high risk for fetal death. So timely intervention can reduce complications like abruption, IUGR and stillbirth.

Second leading cause of IUFD in our study was diabetes mellitus (23.9\%). Among them majority (19.15\%) were GDM, which was higher than the other studies [5] [7] [10] [12] where those were $3.62 \%, 3.8 \%, 4.92 \%, 1.25 \%$ respectively. All the patients came to our hospital with high level of blood sugar and most of the GDM were diagnosed first time after admission. Increasing awareness of the condition among the patients and ensure for recieving proper antenatal care in the right time can help to reduce the incidence.

Anaemia (20.7\%), Abruption (5.3\%) and IUGR (4.8\%) were found in our study. Almost similar observation was reported by other studies [7] [11]. All the cases were iron deficiency anaemia. So, iron supplement, deworming and con- 
sumption of nutritious diet during pregnancy can reduce the anaemia as well as the complications of anaemia.

In this study incidence of oligohydramnios \& hypothyroidism were same (11.2\%) as aetiological factors, which was higher than the study [5] [10]. Where oligohydramnios was $8.19 \%$ and $3.62 \%$ respectively. Hypothyroidism was seen in another study [7] where it was (10.1\%) near to our study.

Maternal infection is one of the important causes of IUFD. In our study it was $9.6 \%$ of the cases almost similar to the study [8] [11] where it was $8.7 \%$ and 9.23\% respectively. Early diagnosis and proper management can prevent the incidence. In our study, malpresentation was $7.44 \%$ of the IUFD which was higher than the study [5] where it was $0.72 \%$.

Congenital anomalies of foetus are another important causes of IUFD. In our study it was $4.8 \%$ of cases, which was higher than the study [5] \& less than the study [10] where the cases were $2.17 \%$ and $21 \%$ respectively.

$4.3 \%$ of cases of IUFD were associated with cord accident in this study which was less than the study [10] [11] where the cases were $6.6 \% \& 12.4 \%$ respectively.

In this study, no causes were found in $24.5 \%$ of the cases which was less than the study [8] [11] \& higher than the study [5] [10] where the cases were $51.9 \%$, $26.15 \%$ and $14.49 \%, 19.67 \%$ respectively.

Regarding maternal complications, $\mathrm{PPH}$ occurred in $11.2 \%$ cases which was much less than the study [13] where it was $21.4 \%$ cases.

Sepsis $2.6 \%$ which was much lower than the another study [14] where it was $10 \%$. These patients were managed in HDU and needed expensive investigations and treatment. In present study $\mathrm{ARF}$ was $0.53 \%$ of cases which was much less than the study [13] [14] where it was 3.5\% and 3.7\% respectively, those patients needed dialysis. Our study showed DIC in $0.53 \%$ of cases which is also much less than the study [13] [14] where those were $3.5 \%$ and $22.5 \%$ respectively. This patient was managed in ICU and joint consultation with haematologist.

The modes of delivery, the percentage $(86.2 \%)$ of vaginal delivery were almost near to the study [5] where it was $84.06 \%$. VBAC was $10.6 \%$ which was much higher than the study [5] which revealed only $1.45 \%$. Percentage of LSCS was $3.2 \%$ which was much less than the study [5] where it was $13.77 \%$. Vaginal delivery was the aim unless there were specific indications for LSCS. The therapeutic options available are Mifepriston and prostaglandins or augmentation by oxytocin. In some cases intrauterine Foley's catheter were used where prostaglandins were contraindicated. Place of cesarean section in a case of IUFD is limited. The most common causes were placenta previa, previous history of cesarean section (two or more) and transverse lie.

Regarding gender of the babies, in this study male babies are more (60\%) than female babies (40\%) which were almost similar to the study [11] where those were $63.07 \%$ and $36.93 \%$ respectively.

Birth weight of babies, maximum babies birth weight were between 1000 to 2500 gm which were almost similar to the study [6]. 
Most of the causes of IUFD in our study were preventable. When a pregnant woman is detected as high risk for development of preeclamsia, which is the most common cause of IUFD in our study, she should be treated aggressively for prevention of preeclampsia as well as adequate control of blood pressure and close monitoring of other parameters like foetal growth, liver and renal functions along with coagulation profile. Timely decision should be taken to avoid the associated complications in general and specially IUFD.

In our study about $19.15 \%$ causes of IUFD due to GDM indicating that proper precautions should be taken for those women who are high risk for development of GDM by pre-conceptional counselling as well as regular antenatal checkup and joint consultation with endocrinologist.

Third leading cause in our study group was anaemia (20.7\%), this was totally preventable by treating anaemia in early pregnancy. This will avoid complications associated with anaemia specially preeclampsia, morbidity and mortality with anaemia and pregnancy.

To summarise the results which can have implications on preventing IUFD, in peripheral centres where antenatal care is provided, health care personnel should be trained to identify the pregnancy as high or low risk. The proper and early diagnosis of high risk cases specially early detection of preeclampsia, anaemia, GDM, previous pregnancy loss will help to reduce the complications. This will also lead timely referral to a higher centre.

\section{Conclusion}

IUFD is a heart-breaking event for the family specially for the parents. Majority of the causes of IUFD can be prevented by preconceptional counselling, regular antenatal checkup as well as proper screening, early diagnosis, treatment, timely intervention of common causes like preeclampsia, diabetes, anaemia, abruptio placenta, maternal high fever and gastroenteritis. So, we can also prevent recurrence of IUFD and it's related maternal complications. Despite advances in diagnostic and therapeutic modalities, a large number of foetal deaths remain unexplained. So, to unravel the complex pathophysiology of IUFDs, research should be continued on IUFDs.

\section{Disclosure}

All the authors declared no competing interest.

\section{Limitations of the Study}

1) This is a single Hospital based study;

2) Data retained may not be applicable to general population;

3) Need multicentre studies to draw valid interference;

4) Due to technical and financial limitations, examinations such as autopsy, cytological studies of fetal tissues and placental histopathology were not done. 


\section{Conflicts of Interest}

The authors declare no conflicts of interest regarding the publication of this paper.

\section{References}

[1] Da Silva, F.T., et al. (2016) Case Definition and Guidelines for Data Collection, Analysis, and Presentation of Maternal Immunization Safety DATA. Vaccine, 34, 6057-6068. https://doi.org/10.1016/j.vaccine.2016.03.044

[2] Malik, R., Khan, N.R., Arif, A., Ayub, S. and Perveen, S. (2016) Common Risk Factors in Patients with Intrauterine Fetal Death. Journal of Postgraduate Medical Institute (Peshawar-Pakistan), 30, 337-341. https://jpmi.org.pk/index.php/jpmi/article/view/1744

[3] Lawn, J.E., Blencowe, H., Waiswa, P., Amouzou, A., Mathers, C., Hogan, D., et al. (2016) Stillbirths Rates, Risk Factors and Acceleration towards 2030. Lancet, 387, 587-603. https://doi.org/10.1016/S0140-6736(15)00837-5

[4] Blencowe, H., Cousens, S., Jassir, F.B., Say, L., Chou, D., Mathers, C., et al. (2016) National Regional, and Worldwide Estimates of Stillbirth Rates in 2015, with Trends from 2000: A Systematic Analysis. Lancet Global Health, 4, e98-e108. https://doi.org/10.1016/S2214-109X(15)00275-2

[5] Bhatia, T., et al. (2016) Clinical Study of Cases of Intrauterine Foetal Death in a Tertiary Centre. International Journal of Research in Medical Sciences, 4, 800-805. https://doi.org/10.18203/2320-6012.ijrms20160521

[6] Sharma, S., Sidhu, H. and Kaur, S. (2016) Analytical Study of Intrauterine Fetal Death Cases and Associated Maternal Conditions. International Journal of Applied Basic Medical Research, 6, 11-13. https://doi.org/10.4103/2229-516X.173986

[7] Kanavi, J.V., et al. (2017) Incidence and Risk Factors of Intrauterine Foetal Demise: A Retrospective Study in a Tertiary Care Centre in India. International Journal of Pregnancy \& Child Birth, 2, 33-36. https://doi.org/10.15406/ipcb.2017.02.00013

[8] Halim, A., et al. (2018) Stillbirth Surveillance and Review in Rural Districts in Bangladesh. BMC Pregnancy and Childbirth, 18, Article No. 224. https://doi.org/10.1186/s12884-018-1866-2

[9] Daga, A.S. and Daga, S.R. (1993) Epidemiology of Perinatal Loss in Rural Maharashtra. Journal of Tropical Pediatrics, 39, 83-85.

https://doi.org/10.1093/tropej/39.2.83

[10] Kumar, A.K., et al. (2017) Clinical Study of Various Risk Factors Associated with Intrauterine Fetal Death. International Journal of Reproduction Contraception, $\mathrm{Ob}$ stetrics and Gynecology, 6, 5293-5298. https://doi.org/10.18203/2320-1770.ijrcog20175231

[11] Sinha, K. and Pandey, S. (2019) Risk Factors in Patients with Intrauterine Fetal Death at Tertiary Referral Centre. Journal of Nepalgunj Medical College, 17, 14-16. https://doi.org/10.3126/jngmc.v17i2.28752

[12] Lawn, J.E., Blencowe, H., Pattinson, R., et al. (2011) Still Births: Where? When? Why? How to Make the Data Count? Lancet, 377, 1448-1463. https://doi.org/10.1016/S0140-6736(10)62187-3

[13] Jamal, S. and Agarwal, S. (2017) IUFD Incidence, Causes and Complications: A Retrospective Study Done at a Tertiary Care Centre. International Journal of Reproduction Contraception, Obstetrics and Gynecology, 6, 5483-5487. 
https://doi.org/10.18203/2320-1770.ijrcog20175265

[14] Patel, S., Thaker, R., Shah, P. and Majumder, S. (2014) Study of Causes and Complications of Intrauterine Fetal Death (IUFD). International Journal of Reproduction Contraception, Obstetrics and Gynecology, 3, 931-935.

https://doi.org/10.5455/2320-1770.ijrcog20141211 